\title{
Prenatal Isolated Mild Ventriculomegaly is Associated with Persistent Ventricle Enlargement at Ages 1 and 2
}

\author{
Amanda E. Lyall ${ }^{1}$, Sandra Woolson ${ }^{1}$, Honor M. Wolfe ${ }^{2}$, Barbara Davis Goldman ${ }^{3,4}$, J.

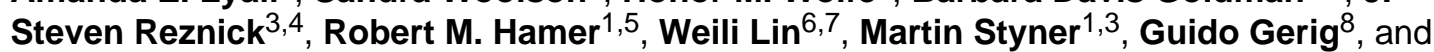 \\ John H. Gilmore ${ }^{1,7}$ \\ ${ }^{1}$ Department of Psychiatry, University of North Carolina, Chapel Hill, NC \\ ${ }^{2}$ Department of Obstetrics and Gynecology, University of North Carolina, Chapel Hill, NC \\ ${ }^{3}$ FPG Child Development Institute, University of North Carolina, Chapel Hill, NC \\ ${ }^{4}$ Department of Psychology, University of North Carolina, Chapel Hill, NC \\ ${ }^{5}$ Department of Biostatistics, University of North Carolina, Chapel Hill, NC \\ ${ }^{6}$ Department of Radiology, University of North Carolina, Chapel Hill, NC \\ ${ }^{7}$ Biomedical Research Imaging Center, University of North Carolina, Chapel Hill, NC \\ ${ }^{8}$ Scientific Computing and Imaging Institute, University of Utah, Salt Lake City, UT
}

\section{Abstract}

Background-Enlargement of the lateral ventricles is thought to originate from abnormal prenatal brain development and is associated with neurodevelopmental disorders. Fetal isolated mild ventriculomegaly (MVM) is associated with enlargement of lateral ventricle volumes in the neonatal period and developmental delays in early childhood. However, little is known about postnatal brain development in these children.

Methods-Twenty-eight children with fetal isolated MVM and 56 matched controls were followed at ages 1 and 2 years with structural imaging on a 3T Siemens scanner and assessment of cognitive development with the Mullen Scales of Early Learning. Lateral ventricle, total gray and white matter volumes, and Mullen cognitive composite scores and subscale scores were compared between groups.

Results-Compared to controls, children with prenatal isolated MVM had significantly larger lateral ventricle volumes at ages 1 and 2 years. Lateral ventricle volume at 1 and 2 years of age was significantly correlated with prenatal ventricle size. Enlargement of the lateral ventricles was associated with increased intracranial volumes and increased gray and white matter volumes. Children with MVM had Mullen composite scores similar to controls, although there was evidence of delay in fine motor and expressive language skills.

Conclusions-Children with prenatal MVM have persistent enlargement of the lateral ventricles through the age of 2 years; this enlargement is associated with increased gray and white

(c) 2012 Elsevier Ireland Ltd. All rights reserved.

Corresponding Author, John H. Gilmore, MD, Department of Psychiatry, 7025 Neurosciences Hospital, CB\# 7160, UNC School of Medicine, Chapel Hill, NC, 27599-7160, 919-966-6971, 919-966-8994 (fax), jgilmore@med.unc.edu.

Publisher's Disclaimer: This is a PDF file of an unedited manuscript that has been accepted for publication. As a service to our customers we are providing this early version of the manuscript. The manuscript will undergo copyediting, typesetting, and review of the resulting proof before it is published in its final citable form. Please note that during the production process errors may be discovered which could affect the content, and all legal disclaimers that apply to the journal pertain. 
matter volumes and some evidence of delay in fine motor and expressive language development. Further study is needed to determine if enlarged lateral ventricles are associated with increased risk for neurodevelopmental disorders.

\section{Keywords}

magnetic resonance imaging; ultrasound; gray matter; white matter; cognitive development

\section{Introduction}

Enlargement of the cerebral lateral ventricles has been observed in many psychiatric disorders including schizophrenia (1-3), autism (4,5), bipolar disorder (6,7), attention-deficit hyperactivity disorder (8) and learning disorders (9). These studies provide indirect evidence that early stages of brain development may be abnormal in patients with these disorders; however, our understanding of the associated underlying neurodevelopmental processes is limited. Assessing brain development in utero may provide a better understanding of genetic or environmental factors influencing the fetal brain during early brain development and may ultimately allow for the identification of early risk factors associated with psychiatric and neurodevelopmental disorders.

Prenatal ultrasonography of the fetal cerebral ventricles is important in the evaluation of the fetal central nervous system (CNS). The width of the atrium of the lateral ventricle, the area where the main body, occipital and temporal horns join together, has proven to be a valuable measure in the clinical assessment of fetal brain development. The average width of the atrium is approximately $0.76 \mathrm{~cm}$ and most studies have found that despite increases in brain volume, the width of the ventricle remains relatively stable throughout gestation (10). Enlarged lateral ventricles in the fetus have been seen in a variety of pediatric brain disorders including progressive hydrocephalus, gray matter migration abnormalities, agenesis of the corpus callosum, aneuploidy, and microcephaly (11-13); this suggests that enlarged ventricle could be indicative of abnormal prenatal development.

Isolated mild ventriculomegaly (MVM) is a prenatal disorder characterized by the enlargement of the lateral ventricles in the absence of associated fetal anomalies (14-16). Prenatal isolated MVM is typically defined as an atrial width greater than $1.0 \mathrm{~cm}$ and less than $1.5 \mathrm{~cm}$, corresponding to $4 \mathrm{SD}$ above the recognized mean (17). It occurs in $0.07 \%$ to $1 \%$ of pregnancies, ranking as one of the most frequently diagnosed cerebral abnormalities in the United States (18). Prenatal isolated MVM is associated with cognitive delays and mild neurodevelopmental abnormalities in early childhood. Long-term studies assessing the outcome of children with isolated MVM are scarce; however, in a case series, we found children with MVM developed ADHD, autism, and learning disorders (19)

MVM has been linked to older maternal age and lower gestational age at birth, both of which have also been associated with higher risk for psychiatric and neurodevelopmental disorders (20). Other studies have found high levels of the anti-viral cytokine interferonalpha in the cord blood of children with MVM, potentially implicating prenatal viral infections such as CMV, varicella zoster and HSV-2 $(21,22)$.

The relationship of prenatal enlarged lateral ventricle size to postnatal brain development in children with isolated MVM is unclear. In our case series, lateral ventricle morphology at 6 years of age generally reflected morphology observed on prenatal ultrasound, suggesting that enlarged prenatal lateral ventricle volume may persist postnatally (19). In a recent study, we found that subjects with fetal isolated MVM demonstrated a persistent enlargement of 
the lateral ventricles on MRI during the neonatal period associated with gray matter volume enlargement and white matter volume reductions (23).

We now report a 1 and 2 year follow-up study of lateral ventricle volumes and brain structure, as assessed by MRI, in our cohort of children with prenatal isolated MVM. We hypothesized that fetal enlargement of the lateral ventricles will persist together with abnormalities in white and gray matter volumes, and will be associated with deficits in cognitive development. Our ultimate hypothesis is that fetal isolated MVM is a structural marker of altered brain development that is associated with a higher risk of specific neuropsychiatric and neurodevelopmental disorders.

\section{Methods}

\section{Subjects}

This study was approved by the Institutional Review Boards of the University of North Carolina (UNC) School of Medicine and the Duke University Medical Center (DUMC). Informed consent was obtained before the prenatal ultrasound assessments and again before each postnatal imaging and developmental assessment. Fetuses with isolated MVM (atrial width $\geq 1.0 \mathrm{~cm})$ or normal lateral ventricle size $(<1.0 \mathrm{~cm})$ identified on routine prenatal screening ultrasound were recruited in the second trimester of pregnancy from the prenatal diagnostic clinics of UNC Hospitals or DUMC. Ultrasound scans were obtained at approximately 22 and 32 weeks gestational age and were performed by trained study ultrasonographers. Ventricle width was determined at the atrium of the lateral ventricle at the tail of the choroid, measuring from inner wall to inner wall in an axial plane (see Figure 1). The width was measured twice and averaged for each visit; both the ventricle nearest and farthest from the transducer were measured when possible.

Forty-eight fetuses identified with isolated MVM were enrolled at the beginning of this study. See Figure 2 for flowchart of subject follow-up, dropouts, and exclusions. We identified age- and sex-matched controls from fetuses presenting with normal ventricular widths $(<10 \mathrm{~mm})$ on prenatal ultrasounds acquired through our on-going study of brain development of normal children (24). Recruitment exclusion criteria for control infants included abnormalities on prenatal ultrasound, major maternal medical illness or prenatal complications, or a history of psychotic disorder in the mother. Exclusion criteria for this analysis included premature birth (gestational age $<33$ weeks), major perinatal complications (asphyxia, seizure, sepsis, pneumonia, stay in neonatal intensive care unit $>$ 24 hours) or abnormality on MRI other than small subdural hematoma common in the neonatal period (25). Two healthy control infants were matched to each MVM infant on the basis of sex, maternal age, gestational age at birth, gestational age at MRI and years of maternal education using propensity scores. Three MVM patients and their matched controls were excluded from the final analysis: one subject with Noonan's syndrome (26), one subject with septo-optic dysplasia (27) and a third subject with Kasabach-Merritt syndrome (28). There were 28 infants with MVM in the final analysis, 25 of which returned at age two. Due to declination to participate in scanning, motion artifacts, or failure of tissue segmentations, usable MRI scans were available for 16 MVM infants at age one and 11 at age two.

\section{MR Image Acquisition}

Images were acquired on a Siemens head-only 3T scanner (Allegra, Siemens Medical System, Erlangen, Germany). Infants were scanned unsedated while asleep, fitted with ear protection and had their heads secured in a vacuum-fixation device at both 1 and 2 year follow up sessions. T1-weighted structural pulse sequences were a 3D magnetization 
prepared rapid gradient echo $($ MP-RAGE TR $=1820 \mathrm{msec}$, inversion time $=400 \mathrm{msec}$, echo time $=4.38 \mathrm{msec}$, flip angle $=7$ degrees, $n=57$ ). Proton density and T2-weighted images were obtained with a turbo spin echo sequence (TSE, TR $=6200 \mathrm{msec}$, TE1 $=20 \mathrm{msec}$, TE2 $=119 \mathrm{msec}$, flip angle 150 degrees). Spatial resolution was $1 \times 1 \times 1 \mathrm{~mm}$ voxel for T1weighted images, $1.25 \times 1.25 \times 1.5 \mathrm{~mm}$ voxel with $0.5 \mathrm{~mm}$ interslice gap for proton density/ T2-weight images. These sequences were chosen to optimize signal to noise and allow for efficient tissue segmentation in this age group using minimal scan times to reduce the likelihood of motion during the scan sequence.

\section{Image Analysis}

Brain tissue was automatically classified as gray matter, white matter, and cerebrospinal fluid (CSF) using an atlas-based expectation maximization segmentation algorithm, called itkEMS, as previously described (29) and utilizing new MVM-focused atlas based on MVM subjects developed after Joshi et al (2004)(30). We subdivided full brain segmentations into cortical and subcortical regions via deformable registration of the parcellation defined in the MVM atlas space to the individual image. The volume of the lateral ventricles was segmented with a user-initialized, semi-automatic surface evolution from the CSF tissue probability map using a level-set evolution tool kit, called itk-SNAP (http://itksnap.org/). A $3 \mathrm{D}$ cutting tool separates left and right lateral ventricles. Intracranial volume (ICV) is the sum of the automatic full brain segmentation results for gray, white, and CSF (ventricles and subarachnoid space) volumes.

\section{Behavioral Analysis}

At each follow-up visit, trained staff administered the Mullen Scales of Early Learning to evaluate performance on 5 subscales: gross motor, fine motor, visual reception, receptive language and expressive language. For each of the subscales, the normative derived T-scores with a mean of 50 and a standard deviation of 10 normalized within circumscribed age groups were determined. A cognitive summary measure, the Mullen Early Learning composite score, with a mean of 100 and a standard deviation of 15 , is derived from the Tscores on the fine motor, visual reception, receptive language and expressive language subtests. This composite reflects general cognitive function in the developing child (31).

\section{Statistical Analysis}

Overall and group descriptive statistics were calculated for the various brain volumes and language variables by year. The means in the MVM and control groups were compared using a two-sided non-parametric Wilcoxon test. Pearson correlations were calculated to determine the relationship between prenatal maximum lateral ventricle width and lateral ventricle volume derived from MRI at years 1 and 2 . The overall correlations and p-values were calculated, as well as the correlations within MVMs and within controls.

General linear models (GLM) were used to investigate group differences in brain volumes adjusting for covariates. The models were run separately for each year and were constructed in three ways: 1) using no covariates, 2) using age at MRI and gender as covariates, 3) using age at MRI, gender, and ICV as covariates. The Mullen composite score and T-scores on subtests were also analyzed using GLMs run separately by year, but did not include age at MRI as a covariate because the derivation of the T-scores and the composite account for age. A t-test was performed to test the differences between groups in least-squares means (the null hypothesis for this t-test is LS means MVM = LS means Controls).

To qualitatively assess longitudinal development of lateral ventricle volume from birth to age 2 years, we combined 1 and 2 year old data from this study with neonatal data from our previous report of neonatal volume for this cohort (23). In this study we examined several 
regions without correcting for multiple comparisons. Findings should be considered to be hypothesis generating and replication is needed in order to verify these findings.

\section{Results}

Demographic information and other descriptive statistics are presented in Table 1. There were no significant differences in birth weight, gestational age at birth, APGAR scores at 5 minutes, or gestational age at MRI between the MVM patients and healthy controls, reflecting matching criteria. Three MVM infants and 3 healthy controls infants had mothers with a history of depression; none of the MVM patients or control subjects had a positive family history of schizophrenia, drug abuse, bipolar disorder or autism spectrum disorders.

Figure 3 presents representative MRI scans of the range of ventricle size observed in the MVM subjects. Children with a prenatal diagnosis of MVM had significantly larger ventricle volumes than matched control subjects at 1 year of age $(42.8 \% p<0.0001$; Figure $4 \mathrm{~A}$, Table 2); this enlargement was significant even when controlling for ICV $(p=0.0002)$. Ventricular enlargement persisted into 2 years of age, with MVM children having significantly larger ventricle volumes than healthy controls $(40.2 \% p=0.0155$; Figure 4B, Table 2); again this enlargement is significant when controlling for ICV $(p=0.0345)$. There was a significant correlation overall between the prenatal maximum atrial width and lateral ventricle volume at 1 year $(r=0.6307, p<.0001)$ and 2 years of age $(r=.6356, p=.0003)$ (Figure 5).

Additional volumetric results are presented in Tables 2 and 3, respectively. At 1 year of age, children with MVM had larger ICVs, though this difference was not statistically significant (4.6\%, $p=0.1810)$. Significantly larger ICVs were seen in children with MVM when compared to control children at 2 years of age $(9.5 \%, p=0.0364)$.

At age 1, there were insignificant increases both in total gray and total white matter volumes. At 2 years of age, children with MVM had significantly larger total gray and total white matter volumes (and trend level increases of cortical gray and cortical white matter), though neither was significant after controlling for ICV. Children with MVM showed no differences in cerebellar volume with and without controlling for ICV (See Table 2 and 3).

Inspection of longitudinal growth indicates that children with MVM and healthy controls followed a similar pattern of ventricle development from birth to 2 years. Both groups display an increase in ventricle volume from birth to 1 year (MVM 82\%, Controls 102\%) and a slight decrease from 1 year to 2 years of age (MVM -3\%, Controls -7\%)(Figure 6).

At 1 and 2 years of age, children with MVM had Mullen Composite scores lower than control children though this reduction was not statistically significant (Table 4). There was a significant reduction in fine motor development at age 2 years and a trend-level reduction at 1 year of age. There was also a trend-level reduction of expressive language scores at 2 years of age.

Of interest in this study are the excluded subjects. The subject with septo-optic-dysplasia was referred to the study with a maximal prenatal atrial width of $1.55 \mathrm{~cm}$. This subject was successfully scanned at 1 year of age and had ventricle volume of $97,738 \mathrm{~mm}^{3}$, well above the mean for MVM subjects. The subject with Noonan's syndrome was scanned at both 1 and 2 years of age and had total lateral ventricle volumes of $19,039 \mathrm{~mm}^{3}$ and $20,480 \mathrm{~mm}^{3}$ respectively; also well above the MVM means for each age. Lastly, the subject with Kasabach-Merritt Syndrome was also scanned at both 1 and 2 years of age and had lateral ventricle volumes of $14,414 \mathrm{~mm}^{3}$ and $12,339 \mathrm{~mm}^{3}$ respectively, within the average range of this MVM cohort. 


\section{Discussion}

Our study is the first to analyze the natural history of prenatal ventricle enlargement in early childhood. We found that children with prenatally diagnosed MVM demonstrated persistent enlargement of lateral ventricle volume through 2 years of age. MVM children as a group also tended to score lower on the fine motor and expressive language subscales of the Mullen Scale of Early Learning. Maximal prenatal atrial width was also highly correlated with lateral ventricle volumes at both 1 and 2 years of age. Taken together, our results indicate that prenatal lateral ventricle structure may be a biomarker of abnormal postnatal brain development.

Previous studies have found developmental delays in patients with MVM $(13,32)$. Bloom and colleagues (1997) utilized the standardized Bayley Scales of Infant Development and found reductions in the MVM group for both the Psychomotor Development Index (PDI) and the Mental Development Index (MDI) around 22 months of age (33). Beeghly et al (2010) also found similar deficits in children with MVM for motor tasks as measured by PDI scores without exhibiting deficits in cognitive function or adaptive learning (34). In this study, we have demonstrated that our cohort displayed reductions in fine motor skills, as well as mild deficits in expressive language abilities. Our findings support previous research, however, long-term follow-up assessments of these children are necessary to characterize persistent neurodevelopmental effects of prenatally enlarged ventricles.

We found that lateral ventricle enlargement is associated with increases in total brain volume and both gray and white matter volumes. The fetuses with MVM are typically identified in mid- $2^{\text {nd }}$ trimester (18-20 weeks), a point in development when neurogenesis and migration are not yet complete (35), thus enlargement of the ventricle may partially precede the majority of gray and white matter development. The increased white and gray matter volumes in MVM children suggest that the increased brain size and tissue volumes could be a consequence of prenatal ventricle enlargement. Importantly, we found a similar pattern of lateral ventricle enlargement and associated increases in gray matter volumes on neonatal MRI in boys (but not girls) at genetic high risk for schizophrenia (36).

Little is known about determinates of prenatal lateral ventricle volume. Inflation of the lateral ventricles occurs early in development before the generation of the choroid plexuses. Studies in zebrafish show that a $\mathrm{Na}^{+} \mathrm{K}^{+}$ATPase ion pump generates osmotic gradients in the ventricular lumen and is responsible for inflation and maintaining proper intraventricular pressure throughout development (37). Aberrant modulation of intraventricular pressure after neurulation could be responsible for ventricular enlargement. After neural tube closure and inflation, it has been hypothesized that neuroepithelial cells constituting the walls of the lateral ventricle secrete embryonic cerebrospinal fluid (eCSF) (37). eCSF is different from adult CSF as it contains over 200 different proteins including proteoglycans, growth factors and extracellular matrix proteins, believed to support early neuronal survival $(38,39)$. In rat embryos, early disruption of proteoglycan synthesis causes changes in eCSF osmolality that result in enlargement of the ventricles (40).

During early gestation, eCSF growth factors support the primary population of cortical progenitor neurons located along the walls of the lateral ventricle (41). Increased surface area of the lateral ventricle walls in MVM may result in a larger number of progenitor neurons and corresponding increase in the production of neurons and glia. Studies have found a correlation between ventricle size and the amount of neuronal cell proliferation within the corresponding periventricular region (42). The thickness of the subventricular zone has been shown to predict sites of gyral and sulcal formation in macaques (41). 
The movement of eCSF has also been implicated in regulating cortical development. Sawamoto and colleagues (2006) demonstrated that the flow of eCSF within the lateral ventricle influences migration of neuroblasts to the olfactory bulb in mice (43). An abnormally enlarged lateral ventricle could potentially have abnormal eCSF flow altering migration of neurons and downstream cortical development.

Increased lateral ventricle size has also been associated with an increased risk of neurodevelopmental disorders. In schizophrenia, enlarged lateral ventricle size is reported in $77 \%$ of studies and it is considered one of the more consistent findings on MRI and it tends to be present early in the course of the illness (44-46). As noted above, we found lateral ventricle enlargement in males at high risk for schizophrenia in the neonatal period (36). Many transgenic mouse models utilized to investigate the neurobiology of schizophrenia and other neurodevelopmental disorders do display enlarged lateral ventricles. For example, Disrupted in schizoprhrenia-1 (DISC1) dominant negative transgenic mice have enlarged lateral ventricle size as well as behavioral abnormalities characteristic of schizophrenia including hyperactivity, anhedonia and disturbances in sensory-motor gating. (47). Inducible hDISC1 transgenic mouse models have also been shown to demonstrate gender-specific behavioral phenotypes associated with mood disorders, such as elevated aggression, depression-like symptoms in female mice and increased responses to stimulants in males (48). Type III-NRG1 heterozygous mutants displayed increased lateral ventricle size as well as other behavioral characteristics of schizophrenia such as deficits in sensorimotor gating and memory impairment (49). Interestingly, a recent study found that first-episode patients with schizophrenia who had combinations of risk alleles in NRG1 and DISC1 had 48\% larger lateral ventricle volumes than those with no risk alleles (50).

Our study has several limitations. The number of subjects with MRI scans was limited by those who declined to participate in the scanning as well as unsuccessful scans at follow-up visits. Attrition in the MVM group led to a smaller sample size at 2 years of age. The majority of our MVM cohort (mean atrial width $=1.05 \mathrm{~cm}$ ) falls at the low end of the range $(1.0-1.5 \mathrm{~cm})$ that is clinically considered prenatal MVM. Outcome studies indicate that atrial widths of $1.2 \mathrm{~cm}$ or greater are more often associated with poorer neurodevelopmental outcomes than widths between $1.0-1.2 \mathrm{~cm}(51,52)$. It is important to note that prenatal atrial widths in the 1.0-1.2 range in this study are associated with significant enlargement of the lateral ventricles at both 1 and 2 years of age and associated alterations of total white and gray matter, as well as mild reductions in fine motor and expressive language scores.

In summary, we found that children with prenatal MVM have persistently enlarged lateral ventricle volume through 2 years of age. In concordance with our previous findings (23), we also found associated gray and white matter changes in children with MVM. While overall developmental scores were similar to controls, children with MVM exhibited reductions in fine motor and expressive language skills. Our study indicates that prenatal ventricle size is highly associated with enlarged lateral ventricle volume at both 1 and 2 years and that the overall relative size of the fetal lateral ventricle appears to be conserved during the early postnatal period and beyond. Thus, enlargement of lateral ventricles appear to be structural markers of altered fetal brain development. Future long-term follow-up studies are needed to determine if prenatal MVM is associated with high risk of neuropsychiatric disorders.

\section{Acknowledgments}

Supported by NIMH Silvio O. Conte Center MH064065, NICHD HD053000, IDDRC P30 HD003110, NRSA T32 NS007431 and NIH grant U54 EB005149 (NA-MIC). 


\section{References}

1. Wright IC, Rabe-Hesketh S, Woodruff PW, David AS, Murray RM, Bullmore ET. Meta-analysis of regional brain volumes in schizophrenia. Am J Psychiatry. 2000; 157:16-25. [PubMed: 10618008]

2. Chua SE, McKenna PJ. Schizophrenia - a brain disease? A critical review of structural and functional cerebral abnormality in the disorder. Br. J. Psychiatry. 1995; 166:563-582. [PubMed: 7620741]

3. Puri BK, Richardson AJ, Oatridge A, Hajnal JV, Saeed N. Cerebral ventricular asymmetry in schizophrenia: a high resolution 3D magnetic resonance imaging study. In J Psychophysiology. 1998; 34:207-211.

4. Piven J, Arndt S, Bailey J, Havercamp S, Andreasen NC, Palmer P. An MRI study of brain size in autism. Am J Psychiatry. 1995; 152:1145-1149. [PubMed: 7625461]

5. Damasio H, Maurer RG, Damasio AR, Chui HC. Computerized tomographic scan findings in patients with autistic behavior. Arch Neurol. 1980; 37:504-510. [PubMed: 6968201]

6. McDonald C, Zanelli J, Rabe-Hesketh S, Ellison-Wright I, Sham P, Kalidindi S, Murray RM, Kennedy N. Meta-analysis of magnetic resonance imaging brain morphemtetry studies in bipolar disorder. Biol Psychiatry. 2004; 56:411-417. 15. [PubMed: 15364039]

7. Kempton MJ, Geddes JR, Ettinger U, Williams SC, Grasby PM. Meta-analysis, database, and metaregression of 98 structural imaging studies in bipolar disorder. Arch Gen Psychiatry. 2008; 65:1017-1032. [PubMed: 18762588]

8. Lyoo IK, Noam GG, Lee CK, Lee HK, Kennedy BP, Renshaw PF. The corpus callosum and lateral ventricles in children with attention-deficit hyperactivity disorder: a brain magnetic resonance imaging study. Biol Psychiatry. 1996; 40:1060-1063. [PubMed: 8915567]

9. Sanderson TL, Best JJK, Doody GA, Cunningham Owens DG, Johnstone EC. Neuroanatomy of comorbid schizophrenia and learning disability: a controlled study. Lancet. 1999; 354:1867-1871. [PubMed: 10584724]

10. Monteagudo, A.; Haratz-Rubinstein, N.; Timor-Tritsch, IE. Biometry of the Fetal Brain. In: TimorTritsch, IE.; Monteagudo, A.; Cohen, HL., editors. Ultrasonography of the Prenatal and Neonatal Brain. Stamford, CT: Appleton \& Lange; p. 113-117.

11. Wilson RD, Hitchman D, Wittman BK. Clinical follow-up of prenatally diagnosed isolated ventriculomegaly, microcephaly and encephalocele. Fetal Ther. 1989; 4:49-57. [PubMed: 2486026]

12. Bromley B, Frigoletto FD Jr, Benacerraf BR. Mild fetal lateral cerebral ventriculomegaly: Clinical course and outcome. Am J Obstet Gynecol. 1991; 164:863-867. [PubMed: 2003552]

13. Patel MD, Filly AL, hersh DR, Goldstein RB. Isolated mild fetal cerebral ventriculomegaly: Clinical course and outcome. Radiology. 1994; 192:759-764. [PubMed: 7520183]

14. Wax JR, Bookman L, Cartin A, Pinette MG, Blackstone J. Mild fetal cerebral ventriculomegaly: Diagnosis, clinical associations, and outcomes. Obstet Gynecol Surv. 2003; 58:407-414. [PubMed: 12775945]

15. Wyldes M, Watkinson M. Isolated mild fetal ventriculomegaly. Arch Dis Child Fetal Neonatal Ed. 2004; 89:F9-F13. [PubMed: 14711845]

16. Laskin MD, Kingdom J, Toi A, Chitayat D, Ohlsson A. Perinatal and neurodevelopmental outcome with isolated fetal ventriculomegaly: A systematic review. J Matern Fetal Neonatal Med. 2005; 18:289-298. [PubMed: 16390787]

17. Melchiorre K, Bhide A, Gika AD, Pilu G, Papageorghiou AT. Counseling in isolated mild fetal ventriculomegaly. Ultrasound Obstet Gynecol. 2009; 34:212-224. [PubMed: 19644944]

18. Cardoza JD, Goldstein RB, Filly RA. Exclusion of fetal ventriculomegaly with a single measurement: the width of the lateral ventricular atrium. Radiology. 1988; 169:711-714. [PubMed: 3055034]

19. Gilmore JH, van Tol JJ, Lewis Streicher H, Williamson K, Cohen SB, Greenwood RS, Charles HC, Kliewer MA, Whitt JK, Silva SG, Hertzberg BS, Chescheir NC. Outcome in children with fetal isolated mild ventriculomegaly: A case series. Schizophr Res. 2001; 48:219-226. [PubMed: 11295375] 
20. Gilmore JH, van Tol J, Kliewer ME, Silva SG, Cohen SB, Hertzberg BS, Chescheir NC. Mild ventriculomegaly detected in utero with ultrasound: Clinical associations and implications for schizophrenia. Schizophr Res. 1998; 33:133-140. [PubMed: 9789905]

21. Dommergues M, Mahieu-Caputo D, Fallet-Bianco C, Mirlesse V, Aubry MC, Delezoide AL, Dumez Y, Lebon P. Fetal serum interferon-alpha suggests viral infection as the aetiology of unexplained lateral cerebral ventriculomegaly. Prenat Diagn. 1996; 16:883-892. [PubMed: 8938056]

22. Degani S. Sonographic findings in fetal viral infections: a systematic review. Obstet Gynecol Surv. 2006; 61:329-336. [PubMed: 16635273]

23. Gilmore JH, Smith LC, Wolfe HM, Hertzberg BS, Smith JK, Chescheir NC, Evans DD, Kang C, Hamer RM, Lin W, Gerig G. Prenatal mild ventriculomegaly predicts abnormal development of the neonatal brain. Biol Psychiatry. 2008; 64:1069-1076. [PubMed: 18835482]

24. Knickmeyer RC, Gouttard S, Kang C, Evans D, Wilber K, Smith JK, Hamer RM, Lin W, Gerig G, Gilmore JH. A structural MRI study of human brain development from birth to 2 years. J Neurosci. 2008; 28:12176-12182. [PubMed: 19020011]

25. Looney CB, Smith JK, Merck LH, Wolfe HM, Chescheir NC, Hamer RM, Gilmore JH. Intracranial hemorrhage in asymptomatic neonates: prevalence on MR images and relationship to obstetric and neonatal risk factors. Radiology. 2006; 242:535-541. [PubMed: 17179400]

26. Rapaport, R. Hypofunction of the Ovaries. In: Kliegman, RM.; Behrman, RE.; Jenson, HB.; Stanton, BF., editors. Nelson Textbook of Pediatrics. 18th Ed.. Philadelphia, Pa: Saunders Elsevier; 2007. chap 587

27. Matushita JPK, Tiel C, Batista RR, Py M, Gasparetto EL. Septo-optic dysplasia plus clinical presentuation and magnetic resonance findings. Arq Neuropsiquiatr. 2010; 68:315-316. [PubMed: 20464308]

28. Shen W, Cui J, Chen J, Zou J, Ji Y, Chen H. Kasbach-Merritt Syndrome: case reports of successful treatment with partial tumor resection and vincristine chemotherapy. Ann Plast Surg. 2010; 65:361-363. [PubMed: 20733375]

29. Prastawa M, Gilmore JH, Lin W, Gerig G. Automatic segmentation of MR images of the developing newborn brain. Med Image Anal. 2005; 9:457-466. [PubMed: 16019252]

30. Joshi S, Davis B, Jomier M, Gerig G. Unbiased diffeomorphic atlas construction for computational anatomy. NeuroImage. 2004; 23:S151-S160. [PubMed: 15501084]

31. Mullen, EM. Mullen Scales of Early Learning (AGS ed.). Circle Pines, MN: American Guidance Service Inc.; 1995.

32. Vergani P, Locatelli A, Strobelt N, Cavallone M, Ceruti P, Paterlini G, Ghidini A. Clinical outcome of mild fetal ventriculomegaly. Am J Obstet Gynecol. 1998; 178:218-222. [PubMed: 9500477]

33. Bloom SL, Bloom DD, DellaNebbia C, Martin LB, Lucas MJ, Twickler DM. The developmental outcome of children with antenatal mild isolated mild ventriculomegaly. Obstet Gynecol. 1997; 90:93-97. [PubMed: 9207821]

34. Beeghly M, Ware J, Soul J, du Plessis A, Khwaja O, Senapati GM, Robson CD, Robertson RL, Poussaint TY, Barnewolt CE, Feldman HA, Estroff JA, Levine D. Neurodevelopmental outcome of fetuses referred for ventriculomegaly. Ultrasound Obstet Gynecol. 2010; 35:405-416. [PubMed: 20069560]

35. Graff-Peters VB, Hadders-Algra M. Otogeny of the human central nervous system: What is happening when? Early Human Development. 2006; 82:257-266. [PubMed: 16360292] Gilmore JH, Kang C, Evans DD, Wolfe HM, Smith JK, Lieberman JA, Lin W, Hamer RM, Styner M, Gerig G. Prenatal and Neonatal Brain Structure and White Matter Maturation in Children at High Risk for Schizophrenia. Am J Psychiatry. 2010; 167:1083-1091. [PubMed: 20516153]

36. Lowery LA, Sive H. Totally tubular: The mystery behind function and origin of the brain ventricular system. Bioessays. 2009; 31:446-458. [PubMed: 19274662]

37. Miyan JA, Zendah M, Mashayekhi F, Owen-Lynch PJ. Cerebrospinal fluid supports viability and proliferation of cortical cells in vitro, mirroring in vivo development. Cerebrospinal Fluid Res. 2006; 3:2. [PubMed: 16549001] 
38. Zappaterra MD, Lisgo SN, Lindsay S, Gygi SP, Walsh CA, Ballif BA. A comparative proteomic analysis of human and rat embryonic cerebrospinal fluid. J Proteome Res. 2007; 6:3537-3548. [PubMed: 17696520]

39. Alonso MI, Gato A, Moro JA, Barbosa E. Disruption of proteoglycans in neural tube fluid by betaD-xyloside alters brain enlargement in chick embryos. Anat Rec. 1998; 252:499-508. [PubMed: 9845201]

40. Kriegstein A, Noctor S, Martinez-Cerdeno V. Patterns of neural stem and progenitor cell division may underlie evolutionary cortical expansion. Nat Rev Neuroscience. 2006; 7:883-890.

41. Bayer, SA.; Atlman, J. Atlas of human central nervous system development. Boca Raton, Fla.; London: CRC; 2008. The human brain during the early first trimester

42. Sawamoto K, Wichterle H, Gonzalez-Perez O, Cholfin JA, Yamada M, Spassky N, Murcia NS, Garcia-Verdugo JM, Marin O, Rubenstein JL, Tessier-Lavigne M, Okano H, Alvarez-Buylla A. New neurons follow the flow of cerebrospinal fluid in the adult brain. Science. 2006; 311:629632. [PubMed: 16410488]

43. Steen RG, Mull C, McClure R, Hamer RM, Lieberman J. Brain volume in first-episode schizophrenia: Systematic review and meta-analysis of magnetic resonance imaging studies. $\mathrm{Br} \mathrm{J}$ Psychiatry. 2006; 188:510-518. [PubMed: 16738340]

44. Vita A, Peri LD, Silenzi C, Dieci M. Brain morphology in first-episdoe schizophrenia: A metaanalysis of quantitative magnetic resonance imaging studies. Schizophr Res. 2006; 82:75-88. [PubMed: 16377156]

45. McCarley RW, Wible CG, Frumin M, Hirayasu Y, Levitt JJ, Fischer IA, Shenton ME. MRI Anatomy of Schizophrenia. Biol Psych. 1999; 45:1099-1119.

46. Hikida T, Jaaro-Peled H, Seshadri S, Kenichi O, Hookway C, Kong S, Wu D, Xue R, Andrade M, Tankou S, Mori S, Gallagher M, Isizuka K, Pletnikov M, Kida S, Sawa A. Dominant-negative DISC1 transgenic mice display schizophrenia-associated phenotypes detected by measures translatable to humans. Proc Natl Acad Sci USA. 2007; 104:14501-14506. [PubMed: 17675407]

47. Ayhan Y, Abazyan B, Nomura J, Kim R, Ladenheim B, Krasnova IN, Sawa A, Margolis RL, Cadet JL, Mori S, Vogel MW, Ross CA, Pletnikov MV. Differential effects of prenatal and postnatal expressions of mutant human DISC1 on neurobehavioral phenotypes in transgenic mice: evidence for neurodevelopmental origin of major psychiatric disorders. Mol Psychiatry. 2011; 16:293-306. [PubMed: 20048751]

48. Shen S, Lang B, Nakamoto C, Zhang F, Pu J, Kuan S, Chatzi C, He S, Mackie I, Brandon NJ, Marquis KL, Day M, Hurko O, McCaig CD, Riedel G, St. Clair D. Schizophrenia-related neural and behavioral phenotypes in transgenic mice expressive truncated DISC1. J Neuroscience. 2008; 28:10893-10904.

49. Mata I, Perez-Iglesias R, Roiz-Santianez R, Tordesillas-Gutierrez D, Gonzalez-Mandly A, Berja A, Vazquez-Barquero J, Crespo-Facorro B. Additive effect of NRG1 and DISC1 genes on lateral ventricle enlargement in first episode schizophrenia. NeuroImage. 2010; 53:1016-1022. [PubMed: 19913623]

50. Gaglioti P, Danelon D, Bontempo S, Mombro M, Cardaropoli S, Todros T. Fetal cerebral ventriculomegaly: outcome in 176 cases. Ultrasound Obstet Gynecol. 2005; 25:372-377. [PubMed: 15791694]

51. Ouahba J, Luton D, Vuillard E, Garel C, Gressens P, Blanc N, Elmaleh M, Evrard P, Oury JF. Prenatal isolated mild ventriculomegaly: outcome in 167 cases. BJOG. 2006; 113:1072-1079. [PubMed: 16956339] 


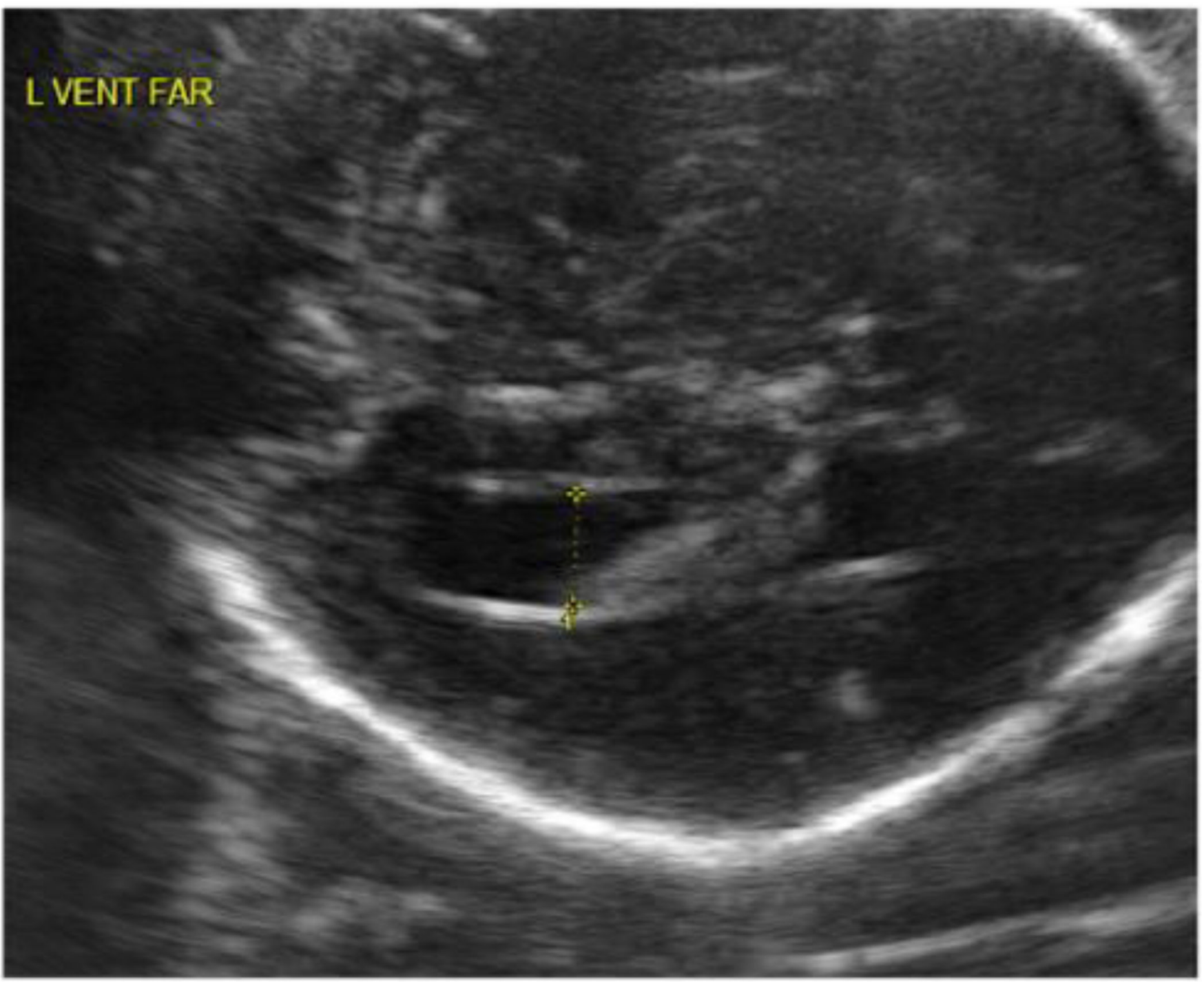

Figure 1.

Representative ultrasound of an MVM subject with measurement of atrial width. 
Initial Enrollment: 48 fetuses with prenatal MVM

- 3 lost to fetal demise

- 2 moved

- 2 lost to follow-up

Neonatal Follow-up: 40 MVM infants

- 1 ventricles normalized

- 4 moved

- 1 died of spinal muscular atrophy type I

- 4 lost to follow-up

1-Year Follow-up:

- 3 excluded

$28 \mathrm{MVM}$ infants 16 usable scans

- 2 mothers declined to participate

- 1 moved

2-Year Follow-up:

$25 \mathrm{MVM}$ infants

11 usable scans

Figure 2.

Flow chart of subject follow-up and dropout. 
A
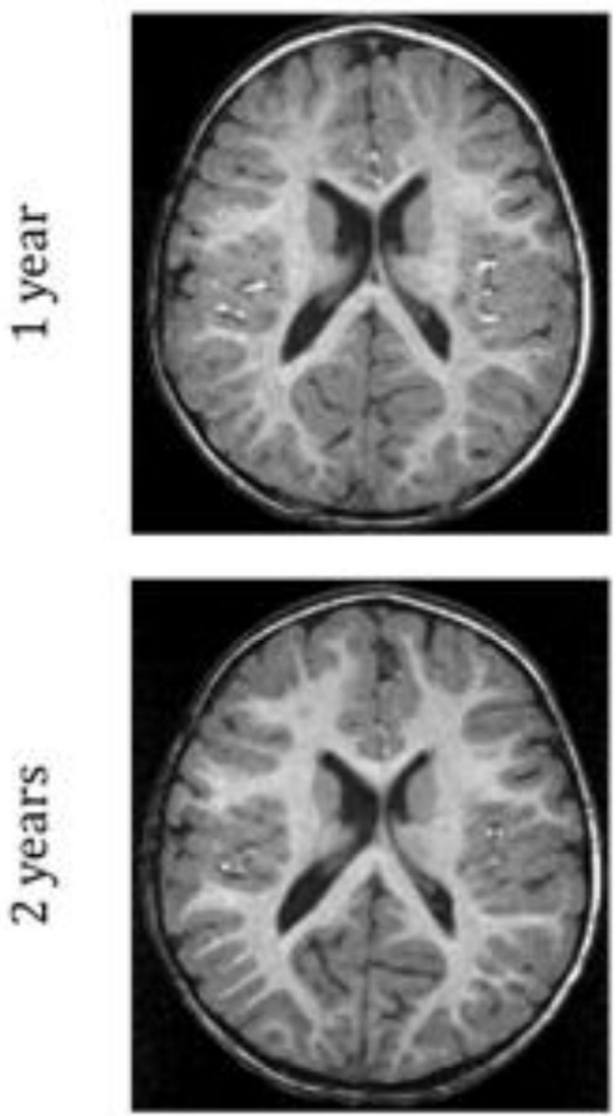

B
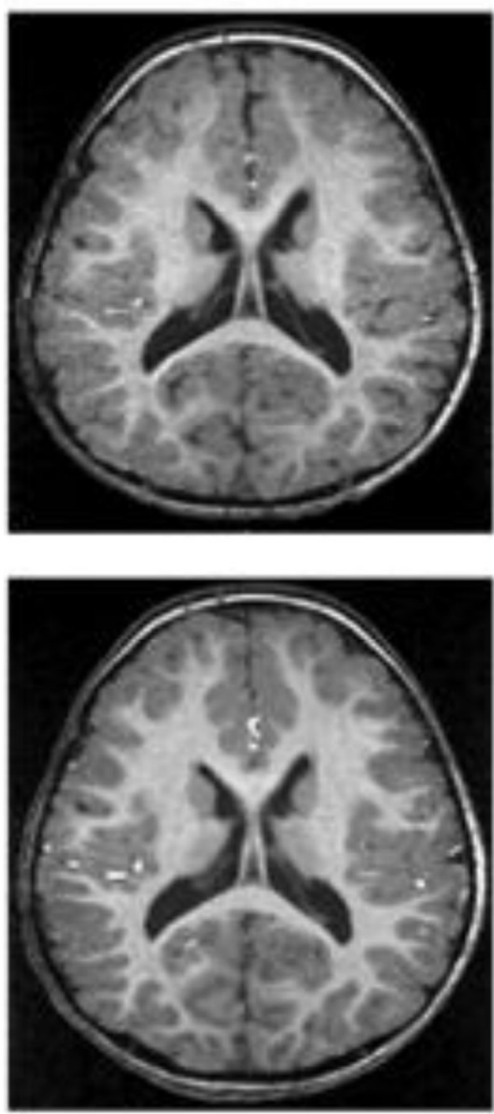

C.
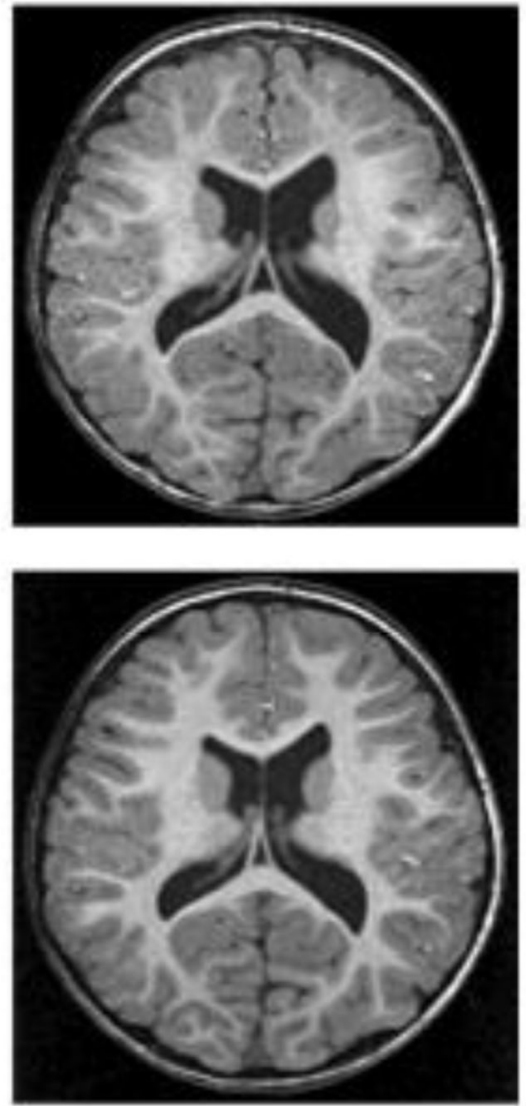

Figure 3.

Representative T1-weighted MR images at 1 and 2 years of age of children with MVM with ventricle sizes ranging from normal (A) to enlarged(C). Note the overall structure, size, and asymmetry of the lateral ventricles are similar at both 1 and 2 years of age. 
A. Year 1

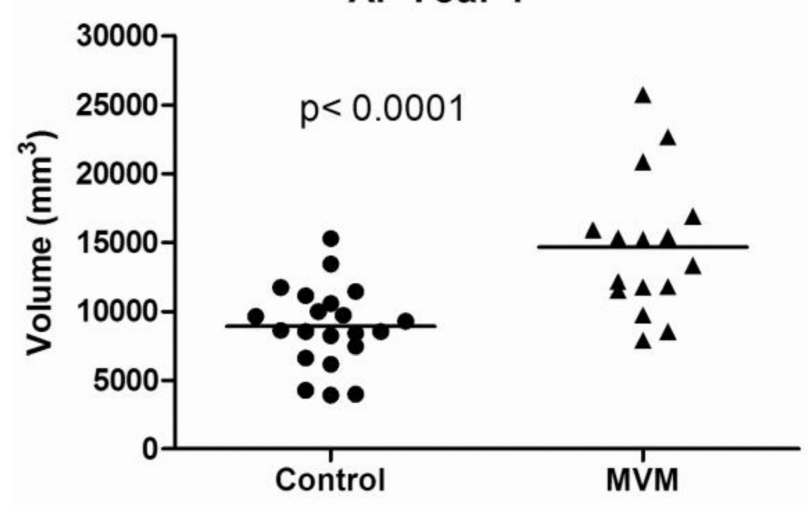

B. Year 2

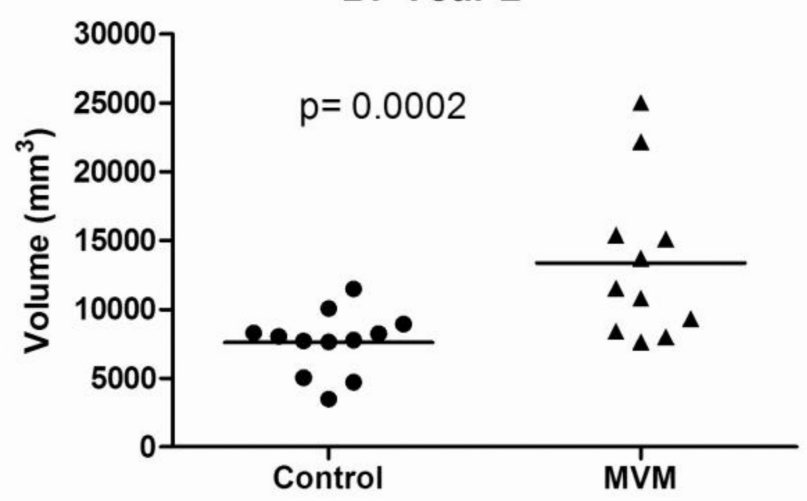

Figure 4.

(A) Raw lateral ventricle volumes in control $(n=25)$ and MVM cases $(n=16)$ at 1 year of age. (B) Raw lateral ventricle volumes in control $(n=18)$ and MVM cases $(n=11)$ at 2 years of age. MVM infants have significantly larger lateral ventricles than control subjects at both 1 and 2 years of age. 
(A) Year 1

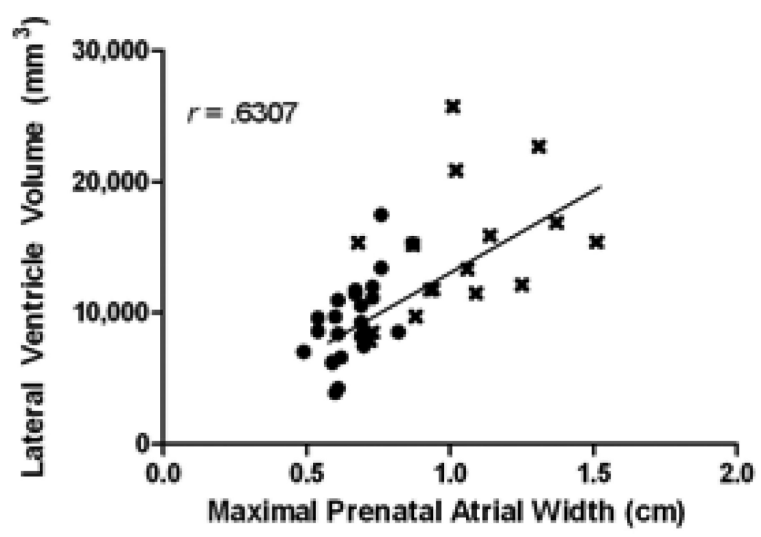

(B) Year 2

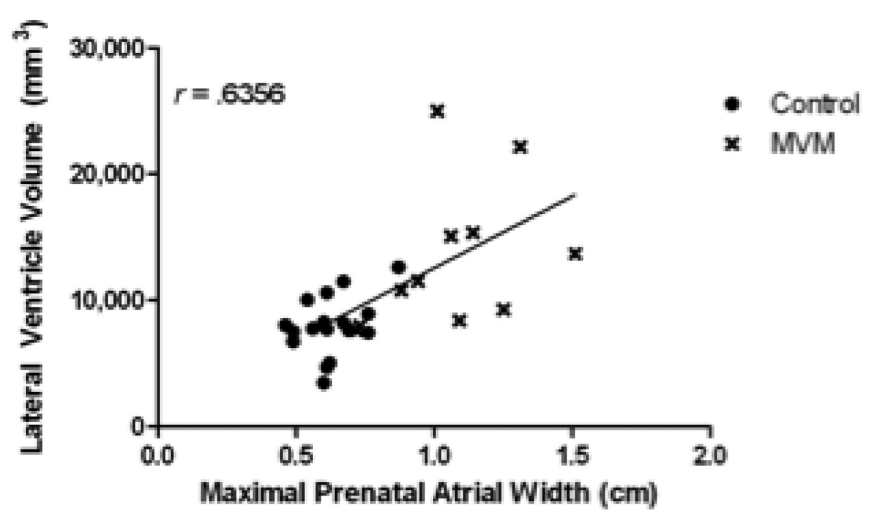

Figure 5.

Maximal prenatal atrial width $(\mathrm{cm})$ is highly correlated with ventricle volume $\left(\mathrm{mm}^{3}\right)$ at 1 and 2 years of age. 


\section{Longitudinal Ventricle Volume}

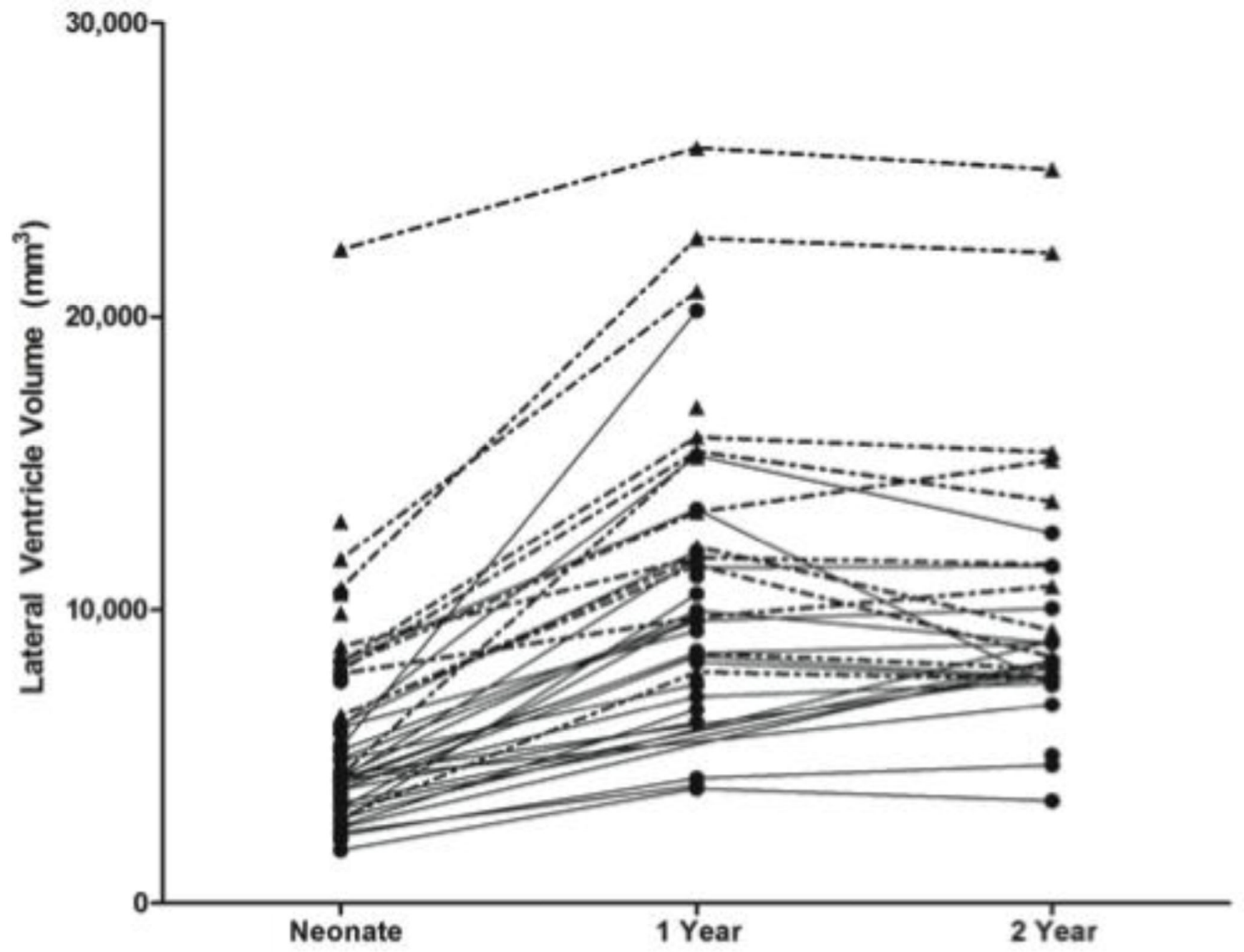

Figure 6.

Longitudinal ventricle volumes for both MVM (dotted line) and control (solid line) subjects from neonate to 2 years. MVM children with larger neonatal volumes tended to stay large at both 1 and 2 years of age. MVM children followed a developmental pattern similar to the healthy controls. 
Table 1

Sample Descriptive Statistics

\begin{tabular}{|c|c|c|c|}
\hline & Control & MVM & $p$ Value \\
\hline \multicolumn{4}{|l|}{ Gender } \\
\hline Male & 39 & 20 & .3873 \\
\hline Female & 17 & 8 & 1.000 \\
\hline \multicolumn{4}{|l|}{ Singleton/Twin } \\
\hline Singleton & 56 & 27 & .3333 \\
\hline Twin & 0 & 1 & \\
\hline \multicolumn{4}{|l|}{ Ethnicity } \\
\hline Caucasian & 46 & 21 & .5188 \\
\hline African American & 9 & 6 & \\
\hline Asian & 1 & 1 & \\
\hline Age at 1 Year MRI (Days) & $650.8(19.69)$ & $660.5(20.33)$ & .1031 \\
\hline Age at 2 year MRI (Days) & 1012(9.23) & $1027(33.72)$ & .2457 \\
\hline Maternal Age at Birth (Years) & $30.06(4.38)$ & $30.13(5.85)$ & .8383 \\
\hline Maternal Education Level (Years) & $15.14(2.67)$ & $15.11(2.73)$ & .9728 \\
\hline Birth Weight (grams) & $3451(508.7)$ & $3572(502.8)$ & .3077 \\
\hline APGAR (at 5 minutes) & $8.91(0.55)$ & $8.89(0.31)$ & .3815 \\
\hline Maximum Prenatal Atrial Width (cm) & $0.64(0.11)$ & $1.05(0.23)$ & $<.0001$ \\
\hline
\end{tabular}

Values are mean (SD). MRI magnetic resonance imaging; MVM, mild ventriculomegaly 


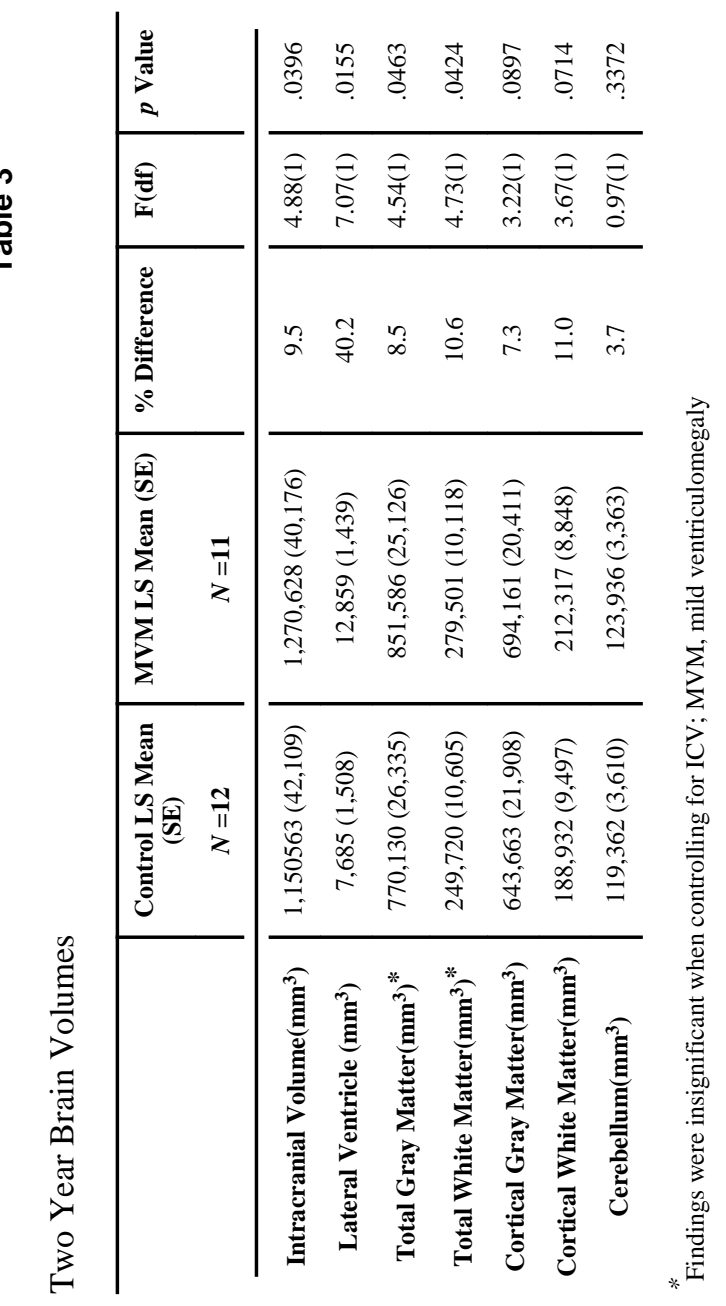

Early Hum Dev. Author manuscript; available in PMC 2013 August 01. 
